\title{
Representações Sociais e Julgamentos Morais de Estudantes Universitários sobre Linchamentos
}

\author{
Maria Edna Silva de Alexandre ${ }^{1, *}$, Lilian Kelly de Sousa Galvão², \& Anderson Scardua ${ }^{2}$ \\ ${ }^{1}$ Universidade Federal da Paraíba, João Pessoa, PB, Brasil \\ ${ }^{2}$ Universidade Federal de Campina Grande, Campina Grande, PB, Brasil
}

\begin{abstract}
RESUMO - O objetivo do presente estudo foi investigar a relação entre as representações sociais e o julgamento moral acerca do linchamento e identificar as atitudes de estudantes de Psicologia e de Ciências Exatas sobre esta prática. Trata-se de uma pesquisa de caráter descritivo e exploratório, realizada com 122 participantes que responderam a um questionário semiestruturado e justificaram suas atitudes diante de um dilema moral. A análise envolveu a análise de conteúdo temática, a estatística descritiva e testes de associação entre variáveis. Os resultados indicaram diferentes formas de representar o linchamento, associadas aos princípios de cada nível de desenvolvimento moral utilizado pelos participantes. De um modo geral, os grupos pesquisados demonstraram uma atitude desfavorável à prática do linchamento, sendo que, entre os favoráveis, predominaram os estudantes de Ciências Exatas.
\end{abstract}

PALAVRAS-CHAVE: linchamentos, representações sociais, julgamento moral, atitudes

\section{The Social Representation and Moral Judgment of College Students on Lynching}

\begin{abstract}
This study aimed to investigate the relationship between social representation and moral judgment on lynching and to identify the position of studentes of Psychology and Exact Sciences on the act. This was a descriptive and explanatory research study, conducted with 122 participants who answered a semistructured questionnaire and justified their attitude towards a moral dilemma. The analysis was done using thematic content analysis, descriptive statistics and tests of association among variables. The results indicated different ways of representing the act of lynching, associated with the principles of each moral development level used by the participants. In general, the studied groups showed a negative view of the practice of lynching, with the favorable ones being predominantly students of Exact Sciences.
\end{abstract}

KEYWORDS: lynchings, social representations, moral judgement, attitude

A violência no contexto brasileiro tem crescido de forma alarmante, originando litígios que desafiam as instâncias oficialmente responsáveis por sua resolução. De modo especial, tem se destacado na mídia e nas conversações cotidianas entre diferentes atores sociais a expressão da violência manifesta através da prática de linchamentos.

Os linchamentos podem ser definidos como um conjunto de atos violentos, praticados por cidadãos em estado de multidão, contra um indivíduo ou grupo acusado de romper alguma norma social e/ou cometido algum crime. Embora nem sempre resulte em morte, o objetivo principal dessa prática consiste na execução sumária dos supostos desviantes, visando puni-los pelo ato cometido e, portanto, restituir a ordem social (Cerqueira \& Noronha, 2004; Martins, 2015; Rodrigues, 2013; Sinhoretto, 2002; Souza $\&$ Menandro, 2002; Vutane, 2013).

Trata-se da adoção de um meio extralegal de prover justiça, através do popular "fazer justiça com as próprias mãos", que contesta o sistema oficial, representado, por vezes, como inoperante. Enquanto os dispositivos formais de promoção de justiça operam, pelo menos em tese, buscando garantir o direito de um julgamento igualitário em função do tipo de crime cometido, o linchamento viola este preceito ao buscar a eliminação sumária da parte conflitante (Cerqueira

*E-mail: edna_silva20@hotmail.com

- Submetido: 23/12/2015; Revisado: 07/06/2016; Aceito: 25/10/2016. 
\& Noronha, 2004; Martins, 2015; Sinhoretto, 2002, 2009; Souza \& Menandro, 2002; Vutane, 2013).

De acordo com Martins (2015), a prática do linchamento tem sido registrada com uma frequência de pelo menos um caso por dia no Brasil, incluindo homens, mulheres e crianças como praticantes. Assim, consubstancia-se um cenário de perpetuação da violência, indicando um processo de incorporação e assimilação desse tipo de "justiça" como medida legítima para resolver conflitos (Cerqueira \& Noronha, 2004; Sinhoretto, 2009; Vutane, 2013). Tal naturalização pode ser observada a partir da proliferação de registros dessas ações, circulando livremente na internet, em canais como o Youtube (Martins, 2015; Rodrigues, 2013).

$\mathrm{Na}$ literatura especializada, além de ser definido como uma forma de justiça, o linchamento é também referido como uma ação pedagógica, materializada em manifestações de exemplaridade das consequências para aqueles que romperem com as regras e/ou cometerem algum crime. Em muitos casos, associam-se aos linchamentos rituais adicionais de violência, como o dilaceramento, o esquartejamento, o fuzilamento e a queima do corpo, ensejando um processo de coisificação da vida e anulação, no outro, da condição de pessoa. Tanto no contexto nacional (Cerqueira \& Noronha, 2004; Martins, 2015; Sinhoretto, 2002, 2009), quanto no âmbito internacional (Goldstein, 2003; Krupa, 2009; Serra, 2008; Vutane, 2013), esses rituais são mais recorrentes em casos de crimes como estupro e incesto, em que a comoção social parece alimentar o desejo de fazer justiça com as próprias mãos.

O linchamento revela-se como um cenário complexo, que desperta preocupação, pois, além dos indivíduos que recorrentemente praticam esse tipo de ação, tem-se outra parcela significativa, constituída por aqueles que $o$ apoiam, alegando ser esta uma medida de legítima defesa e a forma mais eficaz de prover justiça. Esse panorama convida à reflexão de que as ocorrências de linchamentos parecem substituir o significado da pena de morte, embora ela não tenha sido instituída no Brasil. Em virtude disso, vislumbram-se sérias implicações para a convivência social e a preservação do direito à vida, resultando em graves violações dos Direitos Humanos (Goldstein, 2003; Krupa, 2009; Martins, 2015; Ruotti, Freitas, Almeida, \& Peres, 2009; Sinhoretto, 2002).

Apesar de ser inegável a relevância da discussão sobre a prática do linchamento, a literatura científica nacional sobre o assunto ainda é incipiente em quase todas as áreas do conhecimento, especialmente no terreno da Psicologia, sendo associado à Sociologia o acervo mais significativo (Martins, 2015; Rodrigues, 2013; Sinhoretto, 2002, 2009). $\mathrm{Na}$ tentativa de ampliar as possibilidades de compreensão dessa temática, investigou-se o que determinados atores sociais, nesse caso estudantes universitários, pensam sobre a prática do linchamento, utilizando um aporte teórico metodológico constituído pela Teoria das Representações Sociais (Moscovici, 2012) e pela Teoria do Julgamento Moral (Kohlberg, 1969, 1976).
As representações sociais (RS) são compreendidas como fenômenos psicossociológicos que comportam aspectos psicológicos, afetivos, sociais, ideológicos e culturais. Essas representações consistem em uma forma de conhecimento própria do senso comum, sendo elaboradas e compartilhadas coletivamente, através da comunicação social (Moscovici, 2012).

São constituídas por três componentes: a informação, que diz respeito à organização do tipo de conhecimento que o grupo dispõe sobre um dado objeto social; o campo representacional, que remete à expressão dos conteúdos de uma representação, revelando seus significados e valoração, bem como os aspectos mais consensuais e os menos consensuais sobre o objeto socialmente valorizado; e a atitude, que revela uma orientação global, em termos de favorabilidade e desfavorabilidade, em relação ao objeto da representação (Moscovici, 2012).

Essas três dimensões fornecem inteligibilidade ao conteúdo da representação social, facilitando a compreensão de como o grupo se relaciona com o objeto socialmente valorizado. Dessa maneira, salienta-se o caráter orientador de condutas que as RS possuem, revelando que cada representação molda a forma como o indivíduo ou grupo social se vincula a um dado objeto na dinâmica social, justificando a expressão de um comportamento (Moscovici, 2012).

Essa representação está geralmente ligada a um grupo de pertença social, o que indica que um mesmo objeto pode ser alvo de distintas representações, conforme os valores, crenças e experiências partilhadas pelos conjuntos sociais em que são forjadas (Jodelet, 2001; Moscovici, 2012; Shimizu, 2002). Isto explica, em parte, porque alguns grupos têm atitudes favoráveis, enquanto outros manifestam atitudes desfavoráveis, em relação a determinadas práticas sociais, como, por exemplo, a pena de morte e o linchamento. Notase, assim, o poder de transformação da realidade social que uma representação pode assumir, uma vez que é a partir dela que os indivíduos e grupos organizam sua experiência social e passam a fazer o que fazem.

O julgamento moral é concebido por Kohlberg (1969, 1976) como resultante dos juízos de justiça, organizados em uma tipologia de estágios de desenvolvimento moral formada por três níveis. No primeiro nível (Nível I), denominado pré-convencional, a justiça é compreendida como algo que beneficia o próprio indivíduo e as regras do bem e do mal são interpretadas como se fossem externas ao eu, não havendo ainda uma percepção convencional delas. Para os indivíduos que utilizam raciocínios próprios desse nível, o valor moral está localizado em acontecimentos externos, baseado no poder físico de quem estipula a regra. Tal nível abrange o Estágio 1, relacionado à orientação para a punição e a obediência, e o Estágio 2, ligado ao hedonismo instrumental relativista (Biaggio, 2002, 2011; Menin, 2005; Shimizu, 2002). 
No segundo nível (Nível II), intitulado convencional, a justiça está em conformidade com a ordem social, o "eu" mantém identificação com as expectativas dos outros e considera o caráter convencional das regras. Esse nível contempla o Estágio 3, referente à moralidade do bom garoto, de manutenção de boas relações e da aprovação dos outros, e o Estágio 4, de orientação para a lei e a ordem (Biaggio, 2002, 2011; Menin, 2005; Shimizu, 2002).

No terceiro nível (Nível III), pós-convencional, a justiça é entendida como a equidade (Menin, 2005; Rique, Camino, Moreira, \& Abreu, 2013; Shimizu, 2002). Este nível caracteriza-se pela compreensão e aceitação das normas sociais, concebendo-as, todavia, a partir da formulação e consentimento de princípios morais que as transcendem. Assim, o indivíduo diferencia o "eu" das regras e das expectativas do outro e, nos casos em que estas instâncias entram em conflito, baseia seu julgamento nos princípios internalizados em detrimento dos acordos sociais. Nesse nível, situam-se o Estágio 5, da orientação para o contrato social e o Estágio 6, dos princípios éticos universais (Biaggio, 2002, 2011; Menin, 2005; Shimizu, 2002).

Partindo do pressuposto de que existem diferentes níveis de raciocínio moral, questiona-se, no presente estudo, se as pessoas que utilizam argumentos pertencentes a um nível de desenvolvimento moral mais avançado possuem uma forma diferente de representar a prática do linchamento. Investigações já realizadas neste sentido, mas tendo como base outros objetos de estudo, denotaram correspondências entre os raciocínios utilizados para a resolução de conflitos morais e os conteúdos do campo representacional dos participantes. Estes estudos sinalizam, sobretudo, que determinados sistemas de ancoragens permitem a atualização de funcionamentos cognitivos específicos, como a utilização de um tipo de raciocínio moral em detrimento de outro (Menin, 2005; Shimizu, 2002).

Acredita-se que a articulação da Teoria das Representações sociais com a Teoria do Julgamento Moral facilitará uma análise mais ampla do fenômeno do linchamento, permitindo, de um lado, o conhecimento do campo representacional dos sujeitos pesquisados e suas respectivas ancoragens sociais e, de outro, a compreensão do raciocínio utilizado para a resolução de dilemas morais. Ressalte-se que, neste trabalho, mais do que identificar e classificar os sujeitos em níveis mais ou menos avançados de desenvolvimento moral, pretende-se integrar os dados para uma leitura mais ampla e contextualizada do objeto de estudo em questão.

Essa perspectiva também foi enfatizada por Shimizu (2002), ao investigar as possíveis influências que exercem as variações culturais, socioeconômicas e etárias sobre as representações sociais de constructos morais (lei, justiça/ injustiça, moralidade/imoralidade) e sobre os julgamentos morais a eles atribuídos. O estudo foi realizado com jovens estudantes brasileiros e argentinos, denotando, como principais resultados, variações nas representações e julgamentos em função da nacionalidade e do nível socioeconômico dos participantes.

Estudo semelhante foi empreendido por Menin (2005), no tocante às representações sociais de adolescentes brasileiros, marcados por características sociodemográficas distintas, sobre lei, crime e injustiça, discutindo-as também à luz da Teoria do Julgamento Moral. Os resultados mais significativos revelaram uma forte correlação entre as classes sociais dos participantes, o tipo de representação e o julgamento, de modo que quanto menor o status e as condições econômicas, maior o realismo sobre as leis, a severidade dos julgamentos, a representação de uma justiça do tipo expiatória e a dificuldade de reconhecer injustiças.

$\mathrm{O}$ essencial dos referidos estudos consistiu na postura adotada pelas autoras de não reduzir as diferenças a dimensões puramente intraindividuais, justificadas por atrasos e avanços no desenvolvimento moral, mas considerá-las como operações de sentidos possíveis diante das marcações do contexto dos participantes. Isso pressupõe um esforço de integrar análises dos tipos intraindividual, interindividual, intergrupal e societal, conforme sugere Doise (2002). Levando em conta esses pressupostos, o presente estudo objetivou investigar a relação entre as representações sociais e os níveis de julgamento moral acerca do linchamento e identificar as atitudes de estudantes de Psicologia e Ciências Exatas sobre esta prática.

\section{MÉTODO}

\section{Tipo de Pesquisa}

Trata-se de uma pesquisa com abordagem qualitativa e quantitativa, de caráter descritivo e exploratório (Gil, 2010), com amostra não probabilística do tipo intencional. Foi realizada através de estratégias metodológicas mistas, de forma concomitante, gerando "informações em diferentes níveis ou unidades de análise" (Creswell, 2007, p. 33).

\section{Participantes}

Foram adotados os seguintes critérios de inclusão: estudantes maiores de 18 anos; que estavam matriculados no curso de Psicologia ou em qualquer um dos cursos da área de Ciências Exatas; e que assinaram o Termo de Consentimento Livre e Esclarecido. Sublinhe-se que, em função de um conjunto de disciplinas serem comuns aos diversos cursos de 
Ciências Exatas e, portanto, no momento da coleta de dados os alunos estarem presentes em uma mesma sala de aula, não houve restrição quanto à quantidade de participantes por tipo de curso, apenas se exigindo que estivessem vinculados à referida área do conhecimento.

Participaram 122 estudantes universitários da Universidade Federal de Campina Grande (PB), vinculados ao curso de Psicologia $(\mathrm{N}=61)$ e a diferentes cursos da área de Ciências Exatas ( $\mathrm{N}=61)$ : Engenharia Civil $(\mathrm{N}=24)$, Matemática ( $\mathrm{N}=9)$, Engenharia de Minas $(\mathrm{N}=9)$, Engenharia Elétrica $(\mathrm{N}=6)$, Engenharia Agrícola $(\mathrm{N}=3)$, Engenharia de Alimentos $(\mathrm{N}=3)$, Engenharia de Petróleo $(\mathrm{N}=3)$, Engenharia de Materiais ( $\mathrm{N}=2$ ), Engenharia de Produção $(\mathrm{N}=1)$ e Meteorologia $(\mathrm{N}=1)$. Os participantes tinham entre 17 e 33 anos $(M=21,00 ; D P=3,25)$, estavam distribuídos de forma semelhante em relação ao sexo (Feminino-52\%; Masculino-48\%) e, no que concerne à religião, se declararam como Católicos (56\%), Ateus (17\%), Evangélicos (11\%), Cristãos (6\%), Agnósticos (6\%), Espíritas (3\%) e Wiccanos (1\%).

\section{Instrumentos de Coleta de Dados}

Além de uma lista que solicitava aos participantes a informação sobre alguns dos seus dados sociodemográficos (curso, idade, sexo e religião), utilizaram-se dois instrumentos: um questionário aberto, contendo duas perguntas, que objetivavam abarcar, respectivamente, "o que é o linchamento?" e "por que as pessoas cometem linchamentos?"; e um dilema moral, que problematizava a questão do linchamento, a partir do caso divulgado pela mídia jornalística nacional do estupro coletivo de seis mulheres na cidade de Queimadas-PB. O dilema vinha seguido de uma questão sobre a favorabilidade ou não do participante em relação à prática do linchamento e da solicitação da justificativa da resposta (Figura 1).

\section{Procedimentos}

A presente investigação foi aprovada pelo Comitê de Ética em Pesquisa, do Hospital Universitário Alcides Carneiro, da Universidade Federal de Campina Grande (CAAE 42666915.7.0000.5182), respeitando a Resolução 466/2012 do Conselho Nacional de Saúde, que trata da pesquisa com seres humanos (Brasil, 2012). Os instrumentos foram respondidos de forma individual pelos participantes, mas em situação coletiva no contexto da sala de aula.

\section{Análise dos Dados}

As respostas das questões abertas do questionário, que buscaram apreender as representações sociais sobre o linchamento, foram analisadas através da Técnica de Análise de Conteúdo Temática, proposta por Bardin (2011), identificando-se seis categorias temáticas. Estas categorias são excludentes, sendo que as respostas dos participantes poderiam conter mais de uma categoria de análise. Este aspecto serve para explicar o fato de a soma destas categorias ter ultrapassado $100 \%$.

Quanto aos dados oriundos do segundo instrumento, foram identificados e contabilizados os posicionamentos atitudinais relativos à concordância com o linchamento, enquanto que as justificativas foram categorizadas segundo dois critérios, por conteúdo temático e conforme a tipologia

\section{DILEMA DA VIDA REAL: O CASO DO ESTUPRO COLETIVO DE QUEIMADAS-PB}

O que era para ser apenas mais uma comemoração de aniversário resultou em um estupro coletivo, seguido de mortes e esquartejamentos dos corpos na cidade de Queimadas, interior da Paraíba. O crime ocorreu no dia 12 de fevereiro de 2012, quando 10 homens mascarados e armados invadiram a casa onde estava acontecendo a festa, simularam um assalto, amarraram e vendaram 6 mulheres e em seguida realizaram um estupro coletivo. Todos os detalhes foram planejados, inclusive um repertório de músicas religiosas para impedir que os vizinhos ouvissem os gritos das vítimas. $\mathrm{O}$ estupro foi ofertado por um irmão a outro como um presente de aniversário. Durante o estupro duas mulheres reconheceram os estupradores e foram executadas a tiros, tendo seus corpos abandonados em diferentes pontos da cidade.

Para despistar as investigações da polícia os próprios mentores do crime denunciaram o caso à polícia, alegando terem sido vítimas de um assalto e ainda participaram do velório das vítimas.

Quando o caso foi noticiado pela imprensa, especialmente via internet, muitas pessoas demonstraram indignação, afirmando que os estupradores deveriam ser linchados em praça pública.

Você também concorda que os estupradores deveriam ser linchados?

Sim ( ) Não ( ) Não sei ( )

Por quê?

Figura 1. Dilema da vida real: o caso do estupro coletivo de Queimadas-PB. 
do julgamento moral de Kohlberg. As categorias, juntamente com os dados sociodemográficos dos participantes e a classificação atitudinal foram inseridos em um banco de dados do programa Statistical Package for Social Science for Windows - SPSS, versão 22. Em seguida, foram realizadas análises descritivas e comparações entre grupos, verificando-se a associação entre variáveis através do teste Qui-quadrado $\left(\chi^{2}\right)$.

\section{RESULTADOS}

\section{Representação Social do Linchamento}

As categorias temáticas, referentes às respostas dadas às perguntas sobre o que é e qual a funcionalidade da prática do linchamento, estão descritas e exemplificadas a seguir:

Violência coletiva. Agrupou as respostas que apresentaram elementos conceituais sobre o linchamento, definindo-o como uma ação coletiva, que pode materializarse através da violência física, psicológica, moral, verbal e visual. Congregou também, em menor proporção, crenças essencialistas de que o linchamento seria um tipo de violência praticada por aqueles que possuem uma condição internalizada de ódio e maldade, podendo, inclusive, ser de ordem genética e instintiva. Estava presente no discurso de $79,5 \%$ dos participantes. Como exemplos, têm-se os seguintes relatos: "várias pessoas se voltam contra uma só, exercendo violência física e psicológica contra a mesma"; "ato de violência física ou moral"; "pode ser um linchamento verbal, visual”; "interiorizado discursos que carregam em si sentimentos de ódio”;

Prática alternativa de justiça. Agrupou respostas que definiram o linchamento como uma prática alternativa e mais efetiva de fazer justiça, motivada, sobretudo, pela descrença na justiça oficial, constituindo-se, então, como uma forma de protesto social. Foi citada por $52,5 \%$ dos respondentes e como exemplos têm-se: "não acham que o judiciário pune de forma suficiente e satisfatória pelos crimes"; "com a ineficiência, corrompimento e omissão de responsabilidade do sistema judiciário brasileiro, muitos acreditam que os linchamentos são a melhor forma de justiça”;

Linchamento como resposta. Reuniu os discursos que se referiram ao linchamento como uma ação de resposta, uma forma de vingança contra indivíduos acusados de ter cometido algum crime, especialmente aqueles considerados hediondos. Estava presente nas respostas de 35\% dos participantes e seus conteúdos podem ser observados nos seguintes exemplos: "lógica do olho por olho dente por dente"; "compensação de um crime, uma resposta”; "ato de repúdio a um indivíduo o qual cometeu algum ato ilícito na sociedade"; "devido a um fato ocorrido, como, por exemplo, um estupro";

Sentimento de impunidade. Incorporou respostas que apontaram aspectos predominantemente afetivos, como o sentimento de impunidade, revolta, comoção e indignação como motivadores da prática do linchamento. Foi mencionada por $34,4 \%$ dos participantes e, como exemplos, têm-se: "por causa do grande sentimento de impunidade"; "a sociedade fica indignada com determinados crimes, o que acarreta em revolta e geral mal estar social"; "comete-se linchamentos por comoção social"; "indignação e revolta”; "às vezes as pessoas realmente estão sensibilizadas";

Prática que fere a dignidade humana. Agrupou respostas de uma dimensão mais valorativa, que ressaltaram o linchamento como uma prática que fere a dignidade humana, o direito à vida e a prerrogativa do acusado de ser julgado oficialmente pelas instâncias competentes. Desta forma, constituiu-se como a única categoria que parece contemplar argumentos contrários à prática do linchamento. Congregou também respostas que apontaram o linchamento como uma ação discriminatória contra grupos minoritários e/ou que divergem ideologicamente da maioria. Estava presente nas respostas de $26 \%$ dos participantes, tendo como exemplos: "colocarem o ser que vai ser linchado num outro patamar, descaracterizando como humano”; “o poder corretivo deve ser exercido pelo estado, sem ferir a dignidade do cidadão"; "preconceito e não aceitação das diferenças seja de raça, cor, sexualidade, religião”;

Ação impulsiva. Referida por 16\% dos participantes, concentrou respostas que circunscreveram o linchamento como uma ação realizada por impulso, que não passa pela dimensão cognitiva de racionalidade, conforme se pode observar nos seguintes trechos: "linchamento é uma atitude impensada"; "é uma atitude tomada por impulso (geralmente) que se age sem pensar de fato"; "uma violência que ocorre/pode ocorrer por irracionalidade das pessoas".

\section{Julgamento Moral sobre o Linchamento}

Em relação à atitude dos participantes sobre a prática do linchamento, apreendida mediante a questão "você também concorda que os estupradores deveriam ser linchados?", 67\% dos participantes não concordaram com tal prática, $16 \%$ se mostraram favoráveis e $17 \%$ afirmaram não saber responder. Em um segundo momento, as frequências dessas atitudes foram analisadas em função das variáveis sociodemográficas curso, sexo e religião.

No que se refere ao curso de pertença dos respondentes, conforme pode ser observado na Figura 2, os estudantes 


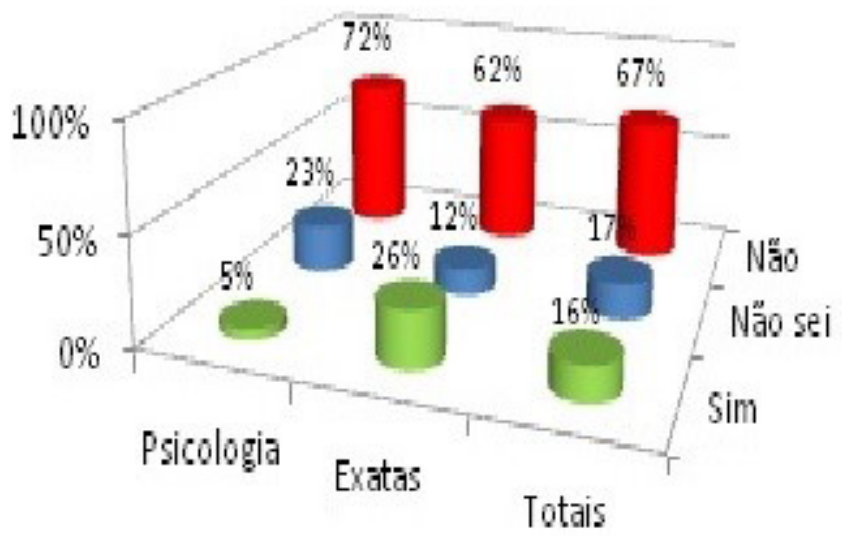

Figura 2. Concordância com o Linchamento considerando o curso de pertença dos participantes.

de Exatas (26\%) demonstraram maior favorabilidade à prática do linchamento do que os de Psicologia (5\%); os estudantes de Psicologia (23\%) obtiveram um maior número de respostas indefinidas do que os de Exatas (12\%); e os discentes de Psicologia (72\%) foram mais desfavoráveis à prática do linchamento do que os de Exatas $(62 \%)\left[\chi^{2}(3\right.$, $\mathrm{N}=122$ ) $=11,68 ; \mathrm{p}=0,003]$.

Não foram observadas diferenças significativas em relação à concordância dos participantes com a prática do linchamento, quando se analisaram as variáveis sexo $\left[\chi^{2}\right.$ $(2, \mathrm{~N}=122)=2,57 ; \mathrm{p}=0,277]$ e religião $\left[\chi^{2}(12, \mathrm{~N}=122)\right.$ $=16,52 ; \mathrm{p}=0,168]$.

As justificativas dadas à questão "você também concorda que os estupradores deveriam ser linchados?" foram categorizadas segundo dois critérios: por conteúdo temático e por níveis de julgamento moral. Na classificação por conteúdo temático emergiram as seguintes categorias:

Julgados perante a lei $(\mathbf{2 9 , 5 \% )}$. Congregou as respostas que sugeriram que os infratores deveriam ser julgados perante as leis vigentes no país, conforme pode ser observado nos seguintes relatos: "o melhor caminho, o mais justo, ainda é o julgamento realizado pelas autoridades competentes"; "independente do que foi feito, existem leis que devem ser seguidas"; "o linchamento impede que os culpados sejam penalizados por vias legais”;

Ciclo de violência (23,8\%). Agregou as respostas que consideraram a prática do linchamento como uma forma de manter um ciclo de violência e, como exemplos de seus conteúdos, destacam-se: "forma de perpetuar um ciclo de violência"; "violência só gera violência"; "linchar ou condenar a morte os estupradores, não resolverá a questão, tão pouco irá amenizá-la, pelo contrário, multiplica o ódio, a violência, o desrespeito, o horror";

Lei de Talião (21,3\%). Agrupou as respostas que defenderam que os protagonistas da história que cometeram o delito mereciam punição, segundo o princípio da Lei de Talião "olho por olho, dente por dente", como pode ser obervado nestes trechos: "se cometeram tal barbaridade à pessoa, devem sofrer"; "pessoas como estas, em minha opinião não merecem viver"; "não cometeria o ato, mas não lamentaria o linchamento"; "eles têm que pagar o que fizeram";

Punição pela gravidade do crime (17,2\%). Reuniu as respostas que mencionaram que os estupradores deveriam ser punidos em função da gravidade do crime. Como exemplos, podem ser sublinhados: "por se tratar de um caso tão cruel"; "pelo fato de ser estupro merece uma justiça maior"; "estupro é crime e é violência demais para não ser punido”; "foi um ato brutal, repugnante”;

Direito à vida $(4,9 \%)$. Reuniu as respostas que defenderam que todos têm o direito à vida, inclusive aqueles que transgrediram a lei, como pode ser visto nestes exemplos: "ninguém merece ser linchado, ninguém tem o direito de tirar a vida do outro"; "cada um de nós tem o direito à vida";

São seres humanos (3,3\%). Congregou as respostas que afirmaram que os transgressores não deveriam ser linchados porque também são seres humanos, conforme pode ser observado nestes fragmentos: "mesmo cometendo um crime tão alarmante como o estupro, eles são pessoas e apresentam subjetividades"; "acho que ninguém deve ser linchado, violentado ou morto"; "são pessoas, são vidas e ponto".

$\mathrm{Na}$ classificação por níveis de julgamento moral (Kohlberg, 1969, 1976), as respostas foram agrupadas da seguinte forma:

Nível pré-convencional $\mathbf{( 3 8 , 5 \% )}$. Foram incluídos neste nível de desenvolvimento moral os participantes que elaboraram respostas que defenderam uma justiça retributiva expiatória (corretiva), categorizadas como Lei de Talião e Punição pela gravidade do crime; 
Nível convencional $(\mathbf{5 3 , 3} \%)$. Agrupou as respostas em que os participantes defenderam a manutenção da ordem social. Foram adicionadas a este nível as respostas categorizadas como Julgados perante a lei e Ciclo de violência;

Nível pós-convencional $(\mathbf{8 , 2 \% )}$. Reuniu as respostas nas quais os participantes defenderam uma ideia que transcendia as convenções normativas. Assim, foram consideradas neste nível as respostas categorizadas como São seres humanos e Direito à vida.

Ressalta-se a pertinência da categorização de Direito à Vida no nível pós-convencional, com base na literatura sobre o linchamento. O que a literatura sobre o linchamento revela é que, apesar da Declaração dos Direitos Humanos e das leis brasileiras posicionarem o direito à vida como norma, o cenário social tem aplicado a sentença de morte através da legitimação desse tipo de justiçamento para algumas pessoas, como, por exemplo, aquelas acusadas de crimes hediondos. Destaca-se também, o alto número de homicídios, as diversas manifestações de violência contra vários grupos sociais proferidas por criminosos, pela força policial e pelas pessoas ditas de bem, situações que são noticiadas constantemente e que indicam que a lei/norma do direito a vida é negada no cenário nacional. Nesse contexto, as respostas de valorização da vida dos criminosos, apesar do crime cometido, revelam um raciocínio moral mais elevado.

\section{Representações do Linchamento}

Conforme pode ser observado na Tabela 1, existem diferentes formas de se representar o linchamento, associadas aos princípios de cada nível de desenvolvimento moral utilizado pelos participantes. Assim, os participantes que utilizaram raciocínios próprios do Nível I tenderam a descrever o linchamento, sobretudo, como Violência coletiva, seguida por Linchamento como resposta; os participantes do Nível II descreveram o linchamento, principalmente, como Violência Coletiva, seguida por Prática alternativa de Justiça; e os participantes do Nível III definiram o linchamento primeiramente como Violência coletiva, vindo a seguir a categoria Prática que fere a dignidade humana. Vale destacar que a categoria Violência coletiva não discrimina, necessariamente, os grupos em termos de julgamento moral, sendo um tipo de resposta mais objetiva e amplamente compartilhada socialmente como caracterização imprescindível do linchamento.

Tabela 1

Relação entre as representações sociais sobre o linchamento e os julgamentos morais sobre o dilema

\begin{tabular}{|c|c|c|c|c|c|c|c|c|}
\hline \multirow{2}{*}{$\begin{array}{l}\text { Níveis de desenvolvimento } \\
\text { RS linchamento }\end{array}$} & \multicolumn{2}{|c|}{ Nível I } & \multicolumn{2}{|c|}{ Nível II } & \multicolumn{2}{|c|}{ Nível III } & \multicolumn{2}{|c|}{ Totais } \\
\hline & $\mathbf{F}$ & $\%$ & $\mathbf{F}$ & $\%$ & $\mathbf{F}$ & $\%$ & $\mathbf{F}$ & $\%$ \\
\hline Linchamento como resposta & 23 & 20,5 & 19 & 11,8 & 2 & 6,9 & 44 & 14,6 \\
\hline Ação impulsiva & 10 & 8,9 & 9 & 5,6 & 1 & 3,4 & 20 & 6,6 \\
\hline Sentimento de impunidade & 21 & 18,8 & 20 & 12,4 & 2 & 6,9 & 43 & 14,2 \\
\hline Violência coletiva & 37 & 33,0 & 51 & 31,7 & 10 & 34,5 & 98 & 32,5 \\
\hline Prática alternativa de justiça & 19 & 17,0 & 41 & 25,5 & 5 & 17,2 & 65 & 21,5 \\
\hline $\begin{array}{l}\text { Prática que fere } \\
\text { a dignidade humana }\end{array}$ & 2 & 1,8 & 21 & 13,0 & 9 & 31,0 & 32 & 10,6 \\
\hline Totais & 112 & 100,0 & 161 & 100,0 & 29 & 100,0 & 302 & 100,0 \\
\hline
\end{tabular}

Nota. $\left[\chi^{2}(10, \mathrm{~N}=302)=32,5 ; \mathrm{p}=0,050\right]$.

\section{DISCUSSÃO}

Este estudo teve como objetivo investigar a relação entre as representações sociais e os níveis de julgamento moral acerca do linchamento e identificar as atitudes de estudantes de Psicologia e de Ciências Exatas sobre esta prática. A análise dos dados revelou uma multiplicidade de significações atribuídas pelos participantes à prática do linchamento, evidenciando um amplo campo representacional. Observouse também, como resposta para o questionamento inicial, o uso de diferentes tipos de raciocínios morais para justificar a pertinência ou não do linchamento como maneira de agir diante de indivíduos criminosos. Além disso, foram verificadas relações entre esses raciocínios - vinculados a níveis de julgamento morais distintos, conforme a tipologia de Kohlberg - e as formas de representar o linchamento, aspecto que converge para a confirmação, assim como visto em outros estudos (Menin, 2005; Shimizu, 2002), de que dados sistemas de ancoragens implicam em funcionamentos cognitivos específicos. Contudo, fazem-se necessários outros estudos que controlem de forma sistematizada as variáveis de ancoragem para uma compreensão pormenorizada da relação entre as RS do linchamento e o nível de JM moral dos indivíduos. 
No que tange aos conteúdos representacionais, compartilhados por ambos os grupos, sobre a prática do linchamento, pode-se dizer que contemplam os três componentes descritos por Moscovici (2012) como dimensões integrantes de uma representação. Com relação à dimensão da informação, destaca-se a ideia do linchamento como sendo um tipo de violência praticada de forma coletiva, contra indivíduos acusados de terem cometido algum crime.

No que diz respeito ao campo representacional sobre o linchamento, este foi marcado por seis categorias, em que as mais consensuais foram as que o conceberam como violência coletiva, prática alternativa de justiça, linchamento como resposta e sentimento de impunidade. Por outro lado, as menos consensuais fizeram referência ao linchamento como uma prática que fere a dignidade humana, motivada por uma ação impulsiva. Quando analisado o componente atitudinal, de uma maneira geral, os participantes dos dois grupos pesquisados demonstraram uma atitude desfavorável à prática do linchamento, sendo que entre os favoráveis predominaram os estudantes de Ciências Exatas.

Em conformidade com o que afirma Moscovici (2012), essas três dimensões permitem compreender a relação dos grupos com um dado objeto social. Com base nesse pressuposto, pode-se sintetizar que para a maioria dos participantes deste estudo, o linchamento é representado como uma forma de violência coletiva, utilizada como uma medida alternativa de promover justiça contra aqueles indivíduos acusados de prejudicar a ordem social, cometendo crimes.

Assim, a prática desse tipo de justiçamento não é circunscrita como direcionamento primeiro para a resolução de conflitos, mas como uma exceção, materializada como uma resposta de revolta e indignação diante de crimes, especialmente os considerados hediondos, como o estupro. Além disso, a recorrência a essa prática é justificada em função dos sentimentos de impunidade e de descrença na justiça oficial, aspectos que a configuram como sendo mais eficaz, em detrimento daquela agenciada pelo Estado através de seus órgãos competentes.

Para outros participantes, há o reconhecimento dos rituais que compõem e definem o linchamento, acrescentando que se trata de uma ação impulsiva, em que os praticantes não pensam nas implicações geradas. Apontam que não deve ser entendido como um mecanismo de prover justiça, pois fere a dignidade humana, ao atentar contra a vida. Salientam também que independentemente do crime cometido, devese preservar, para os supostos criminosos, o direito de um julgamento formal, relativizado pelo conjunto normativo do país. Além disso, é interessante destacar a denúncia que estes participantes fazem ao ponderar que o linchamento tem se materializado como uma ação discriminatória, atingindo, sobretudo, os grupos minoritários.

Esses aspectos já foram observados em alguns estudos, como o de Sinhoretto (2002) e Vutane (2013), que ao entrevistarem moradores de comunidades onde se registrou a ocorrência de linchamentos, estes justificaram que, apesar das consequências, trata-se de uma medida eficaz para reestruturar e restabelecer a coesão das relações no tecido social, assim como para dar vazão à indignação sentida. Os moradores revelaram, também, o caráter de protesto social que assume o linchamento, tendo como alvo as instituições formais de distribuição de justiça, representadas como inoperantes. Adicionalmente, sinalizaram uma reivindicação de participar ativamente na distribuição das penalidades, pois, ao contrário das práticas herméticas, ritualmente codificadas e atenuantes dos agentes da justiça, as ações populares são compreendidas em sua dimensão concreta, atestando a efetivação da aplicação do castigo, sobretudo através da execução sumária do infrator.

Ao fazer referência a esse crime, Moscovici (2011), apoiado nas ideias de Durkheim, salienta seu caráter de violação das crenças e valores, que produz um choque na consciência comum, o que por seu turno, mobiliza uma resposta da coletividade, com a administração de um castigo. Assim, o crime seria um enfraquecimento dos acordos sociais e o castigo, inclusive aquele materializado pelo linchamento, assumiria a função de energizar as consciências adormecidas e conformadas com a desordem social. O castigo condensa ainda um sentido catártico, objetivando extirpar da dinâmica social o "mal" que atenta contra a moral, evidenciando o desejo coletivo de restituí-la. Nessa perspectiva, o castigo ultrapassaria a lógica de punir o criminoso e servir de exemplo para os infratores potenciais. Seria portanto, uma forma de promover a coesão grupal em prol da afirmação, compartilhamento e manutenção de crenças e valores, garantindo assim a sobrevivência do grupo.

Essas premissas parecem reafirmar algo já observado por alguns autores (Martins, 2015; Sinhoretto, 2002; Vutane, 2013), com relação ao linchamento e também identificado neste estudo. Trata-se da representação do linchamento como uma forma de protesto social, contra a inoperância das instituições responsáveis pela aplicação da justiça, bem como uma reivindicação do grupo, no sentido de preservar os interditos e manter a harmonia comunitária. Todavia, não se pode negar, conforme lembra Moscovici (2011, p.151), que ao longo da história "crimes e castigos que deveriam garantir a coesão moral das sociedades revelaram em seguida uma outra face mais perniciosa".

No caso do linchamento não é diferente, podendo-se inferir as consequências dessa prática para a convivência social, pois, mesmo sendo referido como um protesto social destoa, sobremaneira, de um projeto societário que conflua para a harmonia e a solidariedade. Ao contrário disso, intensifica ciclos de violência e instaura novas formas de injustiça. Consubstancia-se um panorama preocupante, uma vez que a representação do linchamento como uma medida plausível pode orientar e justificar cada vez mais esse tipo de prática. Martins (2015) parece de algum modo atestar isso, ao monitorar as ocorrências de linchamentos no 
Brasil durante os últimos 30 anos e revelar o seu aumento exponencial, chegando a contabilizar um caso por dia.

Tal estatística é inquietante em um país como o Brasil, onde o direito de julgar e de punir é exclusivo do Estado. Pode-se sugerir, então, que a sociedade brasileira tem vivenciado um processo gradativo de transferência de poderes "judiciais" para a sociedade civil, a fim de alimentar um sistema popular de aplicação de justiça retributiva? Talvez seja exagero colocar a problemática nesse patamar, mas convém refletir como essa prática tem contribuído para reestruturar e formar representações sociais sobre o sentido da justiça e o alcance do Estado para provê-la. É preciso considerar, também, que a percepção do sistema de justiça como inoperante consolida a representação do linchamento como justiçamento alternativo. Pode ser que essas representações estejam aguçando as frustrações populares, coadunando meios extralegais de resolução de conflito, como o linchamento. Serra (2008) e Vutane (2013) acreditam que a justiça pelas próprias mãos é utilizada pela população como um mecanismo de apaziguamento da angústia diante do sentimento de insegurança.

Diante disso, é importante investigar o significado atribuído à função do linchamento, apreendendo também se os indivíduos que o promovem estão cientes das iatrogenias sociais que tal prática suscita. Enquanto um esforço exploratório desse tipo de investigação, o presente estudo alerta para a complexidade da questão, destacando que embora alguns participantes tenham repudiado e compreendido o linchamento como uma prática que fere a dignidade humana, muitos outros o aprovaram em sua totalidade e/ou diante de alguns crimes específicos, como o estupro. Parece haver uma categorização de crimes e criminosos que podem ser incluídos em um ou outro sistema de justiçamento (oficial ou extraoficial), fazendo crer que a condição humana e a igualdade de direitos podem ser destituídas em algumas situações, como nos crimes que provocam comoção social. Desse modo, se há momentos em que é legítimo e mais eficaz recorrer ao linchamento, tem-se não a substituição de um sistema oficial por um popular, mas a coexistência de ambos os sistemas no interior da sociedade.

Outros dados deste estudo que permitem alargar a reflexão sobre a temática, dizem respeito às justificativas apresentadas pelos participantes ao serem confrontados com o dilema moral e com a indagação sobre a pertinência do linchamento dos protagonistas da história. Embora uma parcela dos participantes tenha defendido o direito dos criminosos serem julgados perante a lei oficial, denunciando o linchamento como uma forma de perpetuar a violência, ao invés de resolvê-la, outra parcela advoga a seu favor. Os posicionamentos favoráveis resgatam a lógica de justiça compreendida como "olho por olho, dente por dente", que não encontra contentamento nas penalidades aplicadas pelo Estado, sendo necessária uma justiça "maior". Os argumentos se baseiam no tipo de crime, fortalecendo a crença de que, entre outros aspectos, ao praticarem o estupro, os criminosos distanciam-se da condição humana, não "merecendo" mais viver.

Assim, de um lado registra-se a predominância de raciocínios típicos do Nível II de julgamento moral, centrado na manutenção da ordem social, delegando a uma instância superior normativa a administração da punição. De outro lado, observa-se a concorrência de lógicas argumentativas características do Nível I, em que a dimensão da punição e do castigo é supervalorizada, admitindo o linchamento como alternativa viável.

Paralelamente a esses tipos de pensamentos, e em menor proporção, emergiram também outros, que deslegitimam a adesão ao linchamento, sublinhando que apesar da gravidade do delito, os criminosos são seres humanos e, portanto, indiscutivelmente são signatários do direito à vida. Trata-se de formas de pensar típicas do Nível III de desenvolvimento moral, que colocam o direito à vida acima das convenções sociais.

Biaggio $(2002,2011)$ ressalta que, em todas as culturas, a maioria dos sujeitos localiza-se no Nível II de desenvolvimento moral, fazendo uso de raciocínios mais convencionais, sendo poucos os que alcançam o Nível III, o que circunscreve a promoção do pensamento pósconvencional como um desafio a ser transposto. Diante de tal constatação, pode-se perguntar se esse fato se deve a questões de ordem puramente intraindividuais. Certamente que não, pois seria por demais reducionista encerrar a discussão nesse fator.

Como afirmam Sousa Filho, Saltzstein e Scardua (2010), é importante considerar outros aspectos, como, por exemplo, a dinâmica observada nas sociedades atuais, mediatizadas, sobretudo, por perspectivas egocêntricas e instrumentais, pautadas no hedonismo individual. Para estes autores, a hierarquização de valores compartilhados e praticados também é influenciada por fatores históricos, sociais, culturais e políticos, podendo implicar em modificações na dinâmica social, como, por exemplo, no aperfeiçoamento da cidadania.

Neste sentido, vale destacar o estudo de Rique et al. (2013), que buscou identificar os julgamentos morais de estudantes universitários em diferentes contextos políticos. Assim como ocorre na presente investigação, aqueles autores encontraram a predominância do pensamento do tipo convencional, com valorização da legalidade, bem como a supervalorização da punição como prática de justiça. Os referidos autores contextualizaram esses resultados, destacando que o panorama da violência no Brasil e a experiência direta que os participantes têm com ela, podem estar contribuindo para a formulação de juízos centrados na opressão e punição dos criminosos, igualando o significado da justiça com o valor semântico da vingança.

Isso leva a crer que não se trata somente de questões intraindividuais, mas também das experiências sociopsicológicas dos sujeitos. Doise $(2001,2002)$ lembra a importância de, ao se investigar um determinado fenômeno, 
considerar a realidade social de sua produção, tendo em vista que essas ancoragens influenciam a forma como os indivíduos organizam a sua relação e a sua tomada de posição quanto a um dado objeto.

Galvão e Camino (2011), ao investigar os julgamentos morais sobre a pena de morte e a redução da maioridade penal de estudantes do ensino médio e de universitários, identificaram uma significativa favorabilidade, pautada na lógica da punição e princípios morais do tipo Lei de Talião. Cientes daquilo que adverte Doise $(2001,2002)$, tais autoras ponderam que esses resultados não expressam apenas o desenvolvimento moral individual dos participantes, sendo também reflexos das características de suas inserções sociais. Citam, por exemplo, a possível influência da mídia como produtora e difusora de representações sobre essas temáticas, instigando a vingança como solução para o problema da violência.

Acredita-se que essas influências também atravessam os julgamentos morais sobre a prática do linchamento manifestados pelos participantes do presente estudo. Desse modo, procurou-se considerá-los para além das variações intraindividuais, enxergando-os também como produtos das interações interindividuais e intergrupais, levando em conta mais de um nível de análise, conforme proposto por Doise (2002).

Neste estudo, isso pôde ser observado a partir de dois importantes aspectos: a constatação de variações nas atitudes e juízos morais entre os estudantes de uma mesma área; e as diferenças intergrupais, com destaque para a maior favorabilidade à prática do linchamento e valorização do castigo pelos participantes dos cursos de Ciências Exatas. Além disso, deve-se destacar a significativa associação entre as formas de representar o linchamento e os princípios morais mais utilizados pelos participantes e característicos de cada nível do desenvolvimento. Este fato serve de alerta para as marcações sociais que estas representações exercem na formulação dos julgamentos morais identificados.

A ideia de marcações sociais no julgamento moral também é defendida por outros autores, como Emler (1987), Shimizu (2002), Menin (2005) e Castorina (2009). Tais autores alertam para o perigo de conceber a classificação dos juízos como atrasos ou avanços no desenvolvimento moral, resultantes apenas de condições intraindividuais. Para eles, é imprescindível contextualizar esses julgamentos em função das diferentes pertinências históricas, sociais, econômicas, culturais e políticas dos sujeitos e grupos sociais, compreendendo as suas relações e afetações com o objeto em questão.

Ressalte-se que no presente estudo, embora não tenham sido abarcadas todas essas variáveis, foi possível inferir algumas marcações através da integração dos dados referentes às representações sociais e à classificação do julgamento moral. Assim, apesar do reduzido tamanho da amostra investigada, que pode reduzir o alcance das análises efetivadas, sugere-se que a estrutura curricular de cada curso seja uma variável a ser considerada como facilitadora ou não de formas de raciocinar e representar o linchamento. Sabe-se que, diferentemente do que acontece com os cursos de Ciências Exatas, o curso de Psicologia possui uma matriz curricular com mais abertura para a discussão de certas temáticas sociais, como a dos Direitos Humanos. Todavia, isto não constitui a única marcação possível, sobretudo tendo em vista que a vinculação acadêmica é apenas um dentre muitos outros contextos de pertencimentos dos participantes, os quais são atravessados por crenças e valores diversos. Tais aspectos, como pontua Doise (2001), operam como ideias de força, isto é, princípios normativos capazes de tangenciar os comportamentos sociais.

No que concerne ao contexto brasileiro, em que o sistema de justiça denota falhas em sua organização (Martins, 2015), sendo representado como inoperante, pode-se dizer que os julgamentos morais identificados sobre o linchamento são formulados, sobretudo, com base na realidade e experiência cotidiana dos seus habitantes, mais do que impulsionados unicamente por fatores cognitivos. Assim, torna-se compreensível a favorabilidade ao linchamento, como uma forma de contestar e suprir a ineficiência do sistema oficial de justiça. Não se pode negar a importância das capacidades cognitivas, mas convém compreender que elas não devem ser pensadas como elementos exclusivos. Portanto, propõese considerar a dimensão cognitiva como fundamental para a construção do pensamento e a decodificação da experiência real, mas que isto só se torna possível por meio das redes de significação construídas nas interações sociais, em contextos distintos, entre sujeitos e objetos, com marcações sociais diferenciadas.

Esta forma de abordar o fenômeno permite uma compreensão mais ampla dos conteúdos do campo representacional dos sujeitos investigados e como estes conteúdos se associam e/ou influenciam os diferentes raciocínios utilizados na resolução de dilemas morais hipotéticos ou reais. Isto leva a entender que não se trata apenas de classificar/enquadrar tais participantes em níveis específicos de maturidade moral, mas que, diante de uma prática social específica como o linchamento, predomina um tipo de pensamento que converge como ideias de força (Doise, 2001), podendo influenciar condutas na dinâmica social, como tomadas de decisões menos coerentes, por exemplo, com a defesa incondicional da vida.

Nesta perspectiva, pode ser que ao se investigar outros objetos e práticas, esses mesmos participantes apresentem representações e raciocínios morais distintos. Isto vem revelar, entre outros aspectos, que esses constructos sofrem influência das relações que os participantes estabelecem com os objetos no cotidiano de suas interações sociais. Essas relações envolvem graus diferentes de conhecimento sobre o assunto, experiências concretas e afetações variadas.

Diante do exposto, pode-se concluir que os estudos integrando as perspectivas da Teoria das Representações Sociais e do Julgamento moral são possíveis e necessários, 
como forma de acessar diferentes níveis de informações e construir sistemas explicativos mais completos e aproximados da realidade. No que tange às limitações deste estudo, podem ser citados o tamanho da amostra, a utilização de apenas um dilema moral para classificar os julgamentos em relação à prática do linchamento e a escolha de estudantes de apenas duas áreas do conhecimento.

Outra limitação refere-se ao tipo de situação proposta para investigar a favorabilidade ou não quanto à prática do linchamento. Embora tenha consistido na apresentação de um dilema da vida real, o fato de ser uma notícia de jornal não promove o mesmo envolvimento emocional que provocaria uma situação mais próxima dos participantes, fator que possivelmente aumentaria a probabilidade de concordância com o linchamento. Neste sentido, sugere-se a formulações de novos estudos, contemplando, de forma mais abrangente, essas variáveis.

É pertinente investigar, por exemplo, a representação social da justiça, uma vez que de acordo com este estudo, ela parece ser equivalente ao sentido do linchamento, de modo que linchar alguém pode ser compreendido como uma ação justa. Convém atentar, também, para as concepções compartilhadas do que é o ser humano e como estas concepções podem legitimar a prática do linchamento em alguns casos. Além disso, torna-se importante identificar as representações sobre o sistema oficial de justiça brasileiro, pois, além de servir como uma análise situacional pela ótica dos atores sociais, essa identificação pode fornecer elementos para a compreensão das práticas de justiça que ocorrem no seu âmbito, como o linchamento e outros tipos de execução sumária.

\section{REFERÊNCIAS}

Bardin, L. (2011). Análise de Conteúdo. Lisboa: Edições 70.

Biaggio, A. M. B. (2002). Lawrence Kohlberg: ética e educação moral. São Paulo: Moderna.

Biaggio, A. M. B. (2011). Desenvolvimento moral: I. Aspectos Cognitivos. In A. M. B. Biaggio (Org.), Psicologia do desenvolvimento (pp. 214-237, 22 $2^{\mathrm{a}}$ edição). Petrópolis: Editora Vozes.

Brasil. (2012). Resolução 466/2012. Diretrizes e normas regulamentadoras de pesquisas envolvendo seres humanos. Brasília: Ministério da Saúde/Conselho Nacional de Saúde.

Castorina, J. A. (2009). Gerard Duveen: Un enfoque dialéctico para relacionar la teoría de las Representaciones Sociales y la Psicología del Desarrollo. Psicologia da Educação, 29(2), 7-26. Recuperado de http://pepsic.bvsalud.org/pdf/psie/n29/ n29a02.pdf.

Cerqueira, R. T., \& Noronha, C. V. (2004). Cenas de linchamento: Reconstruções dramáticas da violência coletiva. Revista Psicologia em Estudo, 9(2), 163-172. Recuperado de http:// www.repositorio.ufba.br:8080/ri/bitstream/ri/3057/1/v9n2a03. pdf.

Creswell, J. W. (2007). Projeto de Pesquisa: métodos qualitativo, quantitativo e misto ( $2^{\mathrm{a}}$ ed.). Porto Alegre: Editora Artmed.

Doise, W. (2001). Droits de l'homme et force des ideés. Paris: Presses Universitaires de France.

Doise, W. (2002). Da psicologia social à psicologia societal. Psicologia: Teoria e Pesquisa, 18(1), 27-35. Recuperado de http://www.scielo.br/scielo.php?script=sci arttext\&pid $=$ S010237722002000100004\&lng $=$ en\&tlng $=$ pt.

Emler, N. (1987). Socio-moral development from the perspective of social representations. Journal for the Theory of Social Behaviour, 17(4), 371-388. DOI: 10.1111/j.1468-5914.1987. tb00104.x. Acesso em nov. 2015.

Galvão, L. K. S., \& Camino, C. P. S. (2011). Julgamento moral sobre pena de morte e redução da maioridade penal. Psicologia \& Sociedade, 23(2), 228-236. Recuperado de http://www.scielo. br/scielo.php?script $=$ sci arttext\&pid $=$ S010271822011000200 $003 \& \operatorname{lng}=$ en\&tlng $=$ pt.

Gil, A. C. (2010). Como elaborar projetos de pesquisa (5 ed.) São Paulo: Atlas.

Goldstein, D. M. (2003). In our own hands: Lynching, justice, and the law in Bolivia. American Ethnologist, 30(1), 2243. Recuperado de http://www.jstor.org/stable/380520 7?seq=1\#page_scan_tab_contents.
Jodelet, D. (2001). Representações Sociais: Um domínio em expansão. In D. Jodelet (Org.), Representações Sociais (pp. 17- 44). Rio de Janeiro: EDUERJ.

Kohlberg, L. (1969). Stage and sequence: The cognitivedevelopmental approach to socialization. In D. A. Goslin (Ed.), Handbook of socialization theory and research (pp. 347-480). Chicago: Rand McNally.

Kohlberg, L. (1976). Moral stage and moralization: The cognitivedevelopmental approach. In T. Lickona (Ed.), Moral development and behavior: Theory, research and social issues (pp. 31-53). New York: Holt, Rinehart and Winston.

Krupa, C. (2009). Histories in red: Ways of seeing lynching in Ecuador. American Ethnologist, 36(1), 20-39. Recuperado de https://www.academia.edu/ 11443095/ Histories_in Red_Ways_of_Seeing_Lynching_in_Ecuador_American_ Ethnologist

Martins, J. S. (2015). Linchamentos: A justiça popular no Brasil. São Paulo: Editora Contexto.

Menin, M. S. S. (2005). Representações sociais de lei, crime e injustiça em adolescentes. Campinas: Mercado de Letras.

Moscovici, S. (2011). A invenção da sociedade: sociologia e psicologia. Petrópolis: Editora Vozes.

Moscovici, S. (2012). A Psicanálise, sua imagem e seu público. Petrópolis: Editora Vozes.

Rique, J., Camino, C. P. S., Moreira, P. L., \& Abreu, E. L. (2013). Julgamento moral de jovens em diferentes contextos políticos. Revista Arquivos Brasileiros de Psicologia, 65(2), 243-257. Recuperado de http://sociales.redalyc.org/articulo. oa? id=229028926007

Rodrigues, D. (2013). Círculo da punição: o linchamento como cena de acusação e denúncia criminal. DILEMAS: Revista de Estudos de Conflito e Controle Social, 6(4), 625-643. Recuperado de http://revistadil.dominiotemporario.com/doc/ DILEMAS-6-4-Art4.pdf.

Ruotti, C., Freitas, T. V., Almeida, J. F., \& Peres, M. F. T. (2009). Graves violações de direitos humanos e desigualdade no município de São Paulo. Revista Saúde Pública, 43(3), 533540. Recuperado de http://www.producao.usp.br/bitstream/ handle/BDPI/ 9417/art_RUOTTI_Graves_violacoes_de_ direitos_humanos_e_desigualdade_ $2009 . p d f$ ? sequence $=\overline{1}$.

Serra, C. (2008). Linchamentos em Moçambique: Uma desordem que apela à ordem. Maputo: Imprensa Universitária. 
Shimizu, A. M. (2002). Representações sociais e julgamentos morais de jovens: Um estudo intercultural comparando duas abordagens teórico-metodológicas (Tese de doutorado). Faculdade de Filosofia e Ciências de Marília, Universidade Estadual Paulista, Marília, SP, Brasil.

Sinhoretto, J. (2002). Os justiçadores e sua justiça: Linchamentos, costume e conflito. São Paulo: IBCCRIM.

Sinhoretto, J. (2009). Linchamentos: insegurança e revolta popular. Revista Brasileira de Segurança Pública, 4(3), 72-92. Recuperado de http://www.observatoriodeseguranca. org/files/ artigo $\% 20$ jaqueline.pdf.

Souza, L., \& Menandro, P. R. M. (2002). Vidas apagadas: Vítimas de linchamentos ocorridos no Brasil (1990-2000). Revista
Psicologia Política, 4(2), 249-266. Recuperado de http://www. fafich.ufmg.br/ psicopol/pdfv2n4/Capitulo\%204.pdf.

Souza Filho, E. A., Saltzstein, H. D., \& Scardua, A. (2010). Autorepresentação e decisão moral. Revista Interamericana de Psicologia/Interamerican Journal of Psychology, 44(1), 110-119. Recuperado de http://www.redalyc.org/articulo. oa? id=28420640012.

Vutane, J. B. (2013). A problemática de linchamentos públicos em Moçambique - caso especifico dos bairros da cidade de Chimoio (Dissertação de mestrado). Faculdade de Direito, Universidade do Porto, Porto, Portugal. Recuperado de https:// sigarra.up.pt/fdup/pt/teses.tese?P_ALUNO_ID=97617\&p_ processo $=16766$. 